\title{
BMJ Global Health Global health education in UK medical schools: a review of undergraduate university curricula
}

\author{
Natasha Roya Matthews (D), Bethan Davies, Helen Ward
}

To cite: Matthews NR, Davies B, Ward H. Global health education in UK medical schools: a review of undergraduate university curricula. BMJ Global Health 2020;5:e002801. doi:10.1136/ bmjgh-2020-002801

Handling editor Seye Abimbola

Received 1 May 2020

Revised 28 September 2020

Accepted 30 September 2020

\section{Check for updates}

(C) Author(s) (or their employer(s)) 2020. Re-use permitted under CC BY-NC. No commercial re-use. See rights and permissions. Published by BMJ.

Faculty of Medicine, School of Public Health, Imperial College London, London, UK

Correspondence to

Helen Ward;

h.ward@imperial.ac.uk

\section{ABSTRACT}

Introduction In recognition of our increasingly globalised world, global health is now a required component of the medical school curriculum in the UK. We review the current provision of global health education (GHE) in UK medical schools to identify gaps in compulsory teaching.

Methods We conducted a review of the literature to inform a two-part electronic survey of global health compulsory teaching, optional teaching and pre-elective training. Surveys were sent to all 33 UK medical schools for completion by the faculty lead on global health and the nominated final year student representative.

Results Surveys were returned by $29(88 \%)$

medical school faculty and 15 (45\%) medical student representatives; $24(83 \%)$ faculty and $10(67 \%)$ students reported including GHE in the core curriculum; however, there was wide variation in the learning outcomes covered. On average $75 \%$ of faculty and $82 \%$ of students reported covering recommended global health themes 'global burden of disease', 'socioeconomic and environmental determinants of health', 'human rights and ethics', and 'cultural diversity and health', while only $48 \%$ of faculty and $33 \%$ of students reported teaching on 'health systems' and 'global health governance'. Almost all institutions offered optional global health programmes and most offered some form of pre-elective training, although content and delivery were variable.

Conclusion Over the last decade, the inclusion of global health in the core curriculum of UK medical schools has increased dramatically. Yet, despite interest among students, significant gaps are apparent in current GHE. Governing bodies in medical education should establish a comprehensive national strategy to help improve access to fundamental GHE for all medical students.

\section{BACKGROUND}

Global health is defined as 'an area for study, research and practice that places a priority on improving health and achieving equity in health for all people worldwide'. ' Global health education (GHE) is growing, with the expansion of GHE options directed towards medical undergraduates in the UK and elsewhere. ${ }^{23}$ In this increasingly globalised world, global issues such as climate change, migration and international trade laws transcend

\section{Key questions}

What is already known?

- It is well documented by students, health professionals and expert panels that global health is an essential part of compulsory modern medical education.

- Several works including the General Medical Council's Outcomes for graduates, outline core global health learning outcomes for medical students, however, the level of provision of global health education (GHE) across UK medical schools is largely unknown.

What are the new findings?

- According to faculty and students, global health was included in the core curriculum at $83 \%$ and $67 \%$ of UK medical schools, respectively.

- There is large variability in GHE in the compulsory curricula, as well as gaps in learning outcomes covered, particularly within the themes of 'global health governance' and 'health systems'.

- Most institutions offered optional global health programmes, as well as pre-elective training, although content and delivery were varied.

\section{What do the new findings imply?}

- Variation in outcomes covered may indicate a lack of consensus on the definition of 'global health' and what constitutes appropriate global health training for medical students.

- There is still a need for medical schools to recognise and formalise global health in compulsory curricula.

- Governing bodies in medical education should establish a comprehensive national strategy to help improve access to fundamental GHE for all medical students.

geographical boundaries and impact health worldwide. Thus, there is a need for medical students to engage with the discipline of global health in order to work effectively within and outside the UK. Several works by students, health professionals and expert panels highlight the importance of this essential part of compulsory modern medical education. ${ }^{4-11}$ Further, over the last decade, the UK government has developed two government-wide 
global health strategies, recognising the need to engage in global health in our interdependent world, not least to support the National Health Service (NHS) and secure good health for people in the UK. ${ }^{12-14}$

Medical students themselves have been key champions for global health in university curricula and have established a strong network of global health organisations, both at UK universities and internationally, through the International Federation of Medical Students' Associations (IFMSA). ${ }^{5}{ }^{15-17}$ Student global health organisations have driven the development of global health programmes in the UK, ${ }^{18-21}$ the Netherlands, ${ }^{5}{ }^{22}$ the USA, ${ }^{8}$ Canada, ${ }^{23}{ }^{24}$ Australia ${ }^{25}$ and Germany. ${ }^{26}$ A review of US medical schools found that $68 \%$ had active student global or international health interest groups. ${ }^{27}$ In the UK, Students for Global Health (SfGH-formerly Medsin), a network formed in 1995 to address global and local health inequalities, has had active groups in more than 30 medical schools. ${ }^{28}$ As of 2014-2015, SfGH reported they had established and active branches at 28 $(85 \%)$ UK medical schools.

SfGH has played a key role in raising the profile of GHE in UK medical curricula ${ }^{529}$ and has successfully lobbied the General Medical Council (GMC) to include global health in the 2009 edition of Tomorrow's Doctors, a guidance document on which UK medical schools base their curricula. ${ }^{30}$ Working with academics and members of civil society with expertise in GHE, SfGH's GHE Project developed a set of 21 global health learning outcomes for medical students published in 2011. ${ }^{30} 32$ Since then, a systematic review by Harmer $e t a l^{3}$ identified 16 core global health competencies relevant for both medical and non-medical students, of which just three corresponded with global health degree courses offered by more than half of UK universities. Another study conducted among Scottish medical schools identified that although respondents reported the presence of GHE at their institution, there was considerable variation in the amount, methods and quality of content and delivery (Nugent C, Thomas E, 2015).

Despite published documents outlining core learning outcomes and competencies for medical students, there is limited literature showing that medical schools have integrated these requisite global health teaching components within mainstream curricular teaching. We therefore seek to review the current provision of global health teaching, focusing on the core curriculum as compared with the Global Health Learning Outcomes Working Group's outcomes guide. ${ }^{32}$ This will characterise disparities in compulsory global health teaching and help ensure medical schools and governing bodies are kept accountable for providing sufficient GHE to develop health professionals fit for practice in a global workplace. Additionally, the study aims to report on the presence of other forms of GHE: optional teaching for undergraduates with a special interest in global health and pre-elective training, teaching provided to students in preparation for the elective-an educational experience organised by the student themselves that may take place overseas.

\section{METHODS}

\section{Survey design}

We developed a two-part electronic survey targeted at medical school faculty leads on global health (faculty survey) and final year medical student representatives (student survey), using SurveyMonkey, an online survey development platform.

The survey design was informed by a review of published literature conducted via MEDLINE using the MeSH terms 'Global Health' and 'Education, Medical, Undergraduate', as well as the keywords 'global health' and 'education' and 'medic* and (UK). NRM independently reviewed the titles and abstracts of each of the retrieved articles for content relevance. Articles with a focus on a specific subject area within GHE, or without a clear focus on undergraduate medical education in the UK, were excluded. The search was supplemented by expert recommendation to ensure identification of key published and unpublished information.

The survey addressed the categories of GHE outlined by the Global Health Learning Outcomes Working Group ${ }^{32}$ : compulsory teaching, optional teaching and pre-elective training, as literature showed most medical schools rely on a contributory model of global health content alongside the core curriculum, in the form of optional Student Selected Components (SSCs) or Special Study Modules (SSMs), intercalated bachelor of science (BSc) degrees and electives. ${ }^{33}$ The survey aimed to broadly identify all GHE offerings in medical school curricula, with a focus on reviewing coverage of the "proposed learning outcomes for medical students, ${ }^{32}$ extrapolated from the requisite learning outcomes for undergraduate medical education listed in the GMC's Tomorrow's Doctors report. ${ }^{31}$ These learning outcomes are focused on medical education in the UK and are intended for compulsory teaching. ${ }^{32} \mathrm{~A}$ literature review by Harmer $e t a l^{\hat{p}}$ found five other key studies that captured the range of core global health learning outcomes/competencies in the broader literature. NRM undertook a close reading of these studies and incorporated into the review additional broad core global health competencies that were not specifically included in the abbreviated 21 outcomes. Box 1 shows the range of core global health learning outcomes and competencies surveyed, including 'other global health core competencies' distilled from the literature.

A qualitative exploration of the role of student organisations in the development of GHE in UK medical curricula was beyond the scope of this research. The presence of a recognised student organisation focusing on global health was used as a proxy for medical student interest in the field, as per Khan $e t a l \mathrm{~s}^{27}$ review of GHE in US medical schools. To verify which UK medical schools had active SfGH branches, national SfGH leads were contacted directly. 
Box 1 Range of core global health learning outcomes/ competencies reviewed*

Proposed global health learning outcomes for medical students ${ }^{32}$ Global burden of disease

- Discuss communicable and non-communicable disease at the global level.

Discuss the impact of international travel and migration on the diseases seen in the UK.

- Discuss the causes and control of global epidemics.

Socioeconomic and environmental determinants of health

- Demonstrate awareness of the non-clinical determinants of health, including social, political, economic, environmental and gender disparities.

- Examine how health can be distributed unequally within and between populations in relation to socially defined measures.

- Describe how the environment and health interact at the global level.

Health systems

- Discuss the essential components of a health system, using the WHO model.

- Recognise that health systems are structured and function differently across the globe.

- Recognise that the National Health Service has an international workforce and explain the impact of this within the UK and overseas.

- Examine the causes and scale of inequalities in health workforce distribution.

Global health governance

- Demonstrate awareness of the complexity of global health governance, including the roles of international organisations, the commercial sector and civil society.

- Discuss the role of WHO as the international representative body of national governments for health.

Discuss how health-related research is conducted and governed globally.

Human rights and ethics

- Respect the rights and equal value of all people without discrimination and provide compassionate care for all.

- Examine how international legal frameworks impact on healthcare delivery in the UK.

Discuss and critique the concept of a right to health.

- Describe the particular health needs of vulnerable groups and migrants.

- Discuss the role of doctors as advocates for their patients, including the importance of prioritising health needs over other concerns and adhering to codes of professional conduct.

Cultural diversity and health

- Demonstrate understanding that culture is important and may influence behaviour, while acknowledging the dangers of assuming that those from a particular social group will behave in a certain way.

- Communicate effectively with people from different ethnic, religious, and social backgrounds, where necessary using external help.

Work effectively with colleagues from different ethnic, religious and social backgrounds.

Other global health core competencies

- Humanism. ${ }^{58}$

- Taking adequate patient histories and physical examinations in resource poor settings. ${ }^{58}$

- Cost consciousness; using physical diagnosis without high technological support. ${ }^{58}$

\section{Box 1 Continued}

Globalisation and health. ${ }^{259}$

- International elective and exchange opportunities. ${ }^{2}$

- International health and development. ${ }^{2}$

- Analytical skills (skills in epidemiology and in monitoring and evaluation). ${ }^{60}$

- Management and leadership skills. ${ }^{60}$

- Policy analysis and development skills. ${ }^{60}$

*Adapted from Johnson et al. ${ }^{32}$ Panel: Proposed global health learning outcomes for medical students.

\section{Administration of survey}

Survey data for this report were gathered from 21 April to 21 May 2015. At least two reminders, with a further copy of the cover letter and link to the survey, were sent to non-respondents within this period. If multiple responses were received from the same institution, only the first response was accepted.

For the faculty survey, email requests were sent by NRM to all $(n=33)$ medical schools in the UK, inviting the faculty member best able to answer questions about global health teaching in the curriculum to participate in the survey. These emails included a cover letter notifying institutions of the goals of the survey, the definition of global health offered by Koplan et al and a link to the electronic faculty survey. Where possible, the Medical Education Centre (or equivalent) was the first point of contact.

For the student survey, email requests were sent by NRM to all $(n=33)$ medical schools in the UK, asking that they forward the survey to the nominated final year medical student representative. These emails included a cover letter notifying students of the goals of the survey, the definition of global health ${ }^{1}$ and a link to the electronic student survey.

\section{Analysis of survey responses}

Descriptive statistics were calculated for quantitative analysis of the data. To assess compulsory GHE in detail, NRM calculated the mean percentage of responding faculty and students reporting teaching on different global health learning outcomes, as well as the average location of recommended global health themes per years 1-5 of the curriculum, according to medical school faculty. Thematic analysis was conducted for qualitative analysis of free-text responses to 'Please give details of any further information you have about pre-elective training for medical students'. NRM independently examined the data for common themes and combined them to achieve a coherent interpretation.

\section{Patient and public involvement}

During the formative research stage, input on study design and conduct was sought from stakeholders including the Head of the Undergraduate School of Medicine and Project Officer for Curriculum Mapping

Continued 
Table 1 Number and percentage of faculty and students reporting the provision of global health education (GHE) in the medical curriculum, 2014-2015

\begin{tabular}{lllllll}
\hline & $\begin{array}{l}\text { Faculty } \mathbf{n = 2 9} \\
\mathbf{n}(\%)\end{array}$ & $\begin{array}{l}\text { Student } \mathbf{n = 1 5} \\
\mathbf{n}(\%)\end{array}$ & $\begin{array}{l}\text { Faculty } \mathbf{n = 2 9} \\
\mathbf{n}(\%)\end{array}$ & $\begin{array}{l}\text { Student } \mathbf{n = 1 5} \\
\mathbf{n}(\%)\end{array}$ & $\begin{array}{l}\text { Faculty } \mathbf{n = 2 9} \\
\mathbf{n}(\%)\end{array}$ & $\begin{array}{l}\text { Student } \mathbf{n = 1 5} \\
\mathbf{n}(\%)\end{array}$ \\
\cline { 2 - 3 } Category of GHE & Yes & & No & Unsure & \\
\hline Compulsory GHE & $24(83)$ & $10(67)$ & $4(14)$ & $3(20)$ & $1(3)$ & $2(13)$ \\
Optional GHE & $26(90)$ & $13(87)$ & $2(7)$ & $1(7)$ & $1(3)$ & $1(7)$ \\
Preelective training & $20(69)$ & $8(53)$ & $3(10)$ & $7(47)$ & $6(21)$ & $0(0)$ \\
\hline
\end{tabular}

at Imperial College London, as well as experienced members and alumni of SfGH with an interest in GHE. Both faculty and student survey participants were given the opportunity to provide contact details to be kept updated on research outputs. Preliminary findings were disseminated at a student global health event in 2015 and the Association for Medical Education in Europe Conference 2016, as well as to members of SfGH working on GHE.

\section{RESULTS}

Twenty-nine $(88 \%)$ of 33 medical schools responded to the faculty survey and 15 (45\%) of 33 final year medical student representatives responded to the student survey within the time provided. Results are presented according to faculty and students, respectively.

\section{Compulsory teaching}

Of responding medical school faculty and student representatives, $83 \%$ of faculty and $67 \%$ of students reported the provision of GHE in the compulsory medical curriculum (table 1 ).

Table 2 shows the percentage coverage of global health learning outcomes, according to faculty and students, respectively. Survey responses indicated a wide variation in the percentage of medical schools covering each learning outcome in the compulsory curriculum, from $15 \%$ to $100 \%$. Responses from both faculty and students also showed a similar relative coverage ranking, in which four of the five most (Demonstrate awareness of the non-clinical determinants of health, including social, political, economic, environmental and gender disparities; Examine how health can be distributed unequally within and between populations in relation to socially defined measures; Respect the rights and equal value of all people without discrimination and provide compassionate care for all; Discuss the role of doctors as advocates for their patients, including the importance of prioritising health needs over other concerns and adhering to codes of professional conduct) and least represented outcomes (Demonstrate awareness of the complexity of global health governance, including the roles of international organisations, the commercial sector and civil society; Discuss how health-related research is conducted and governed globally; Taking adequate patient histories and physical examinations in resource poor settings; Policy analysis and development skills) corresponded.

\section{Optional teaching}

Most medical school faculty $(90 \%)$ and students $(87 \%)$ reported GHE was available to students as part of the optional curriculum (table 1). The most common modes for delivering optional GHE were special modules (SSC/SSMs) or intercalated Global Health/International Health/Global Public Health degree programmes (table 3). Of faculty members who selected 'other', two mentioned one each of an SSC and SSM not specifically titled global health, but with the potential to cover global health topics, two reported an intercalated degree programme covering global health modules such as a Master of Public Health programme and two referred to global health sessions linked to the elective period. One also highlighted that while not offered at their university; students have the option to complete an intercalated degree in Global Health at another university. Of student respondents, two reported pre-elective training in global health and one mentioned the opportunity to complete a dissertation project.

\section{Pre-elective training}

Respondents from 20 medical school faculty (69\%) indicated there was specific pre-elective training, although six $(21 \%)$ were unsure and three $(10 \%)$ had none (one medical school course was preclinical only and therefore did not have an elective period). Seven (47\%) medical student representatives reported there was no pre-elective training, again, one of whom detailed that their medical school did not facilitate electives as part of their preclinical curriculum (table 1). Institutions provided a variable mix of compulsory and voluntary training for students, ranging from set reading to a single preparatory session, to a series of lectures or workshops or online modules to complete. Specifically, 11 faculty members alluded to pre-elective teaching sessions, while three and one made explicit mention of written materials and online modules, respectively. Very common themes included a focus on health and safety and risk assessment, while several programmes also covered the wider issues of ethics of working abroad and cultural awareness. Two faculty members 


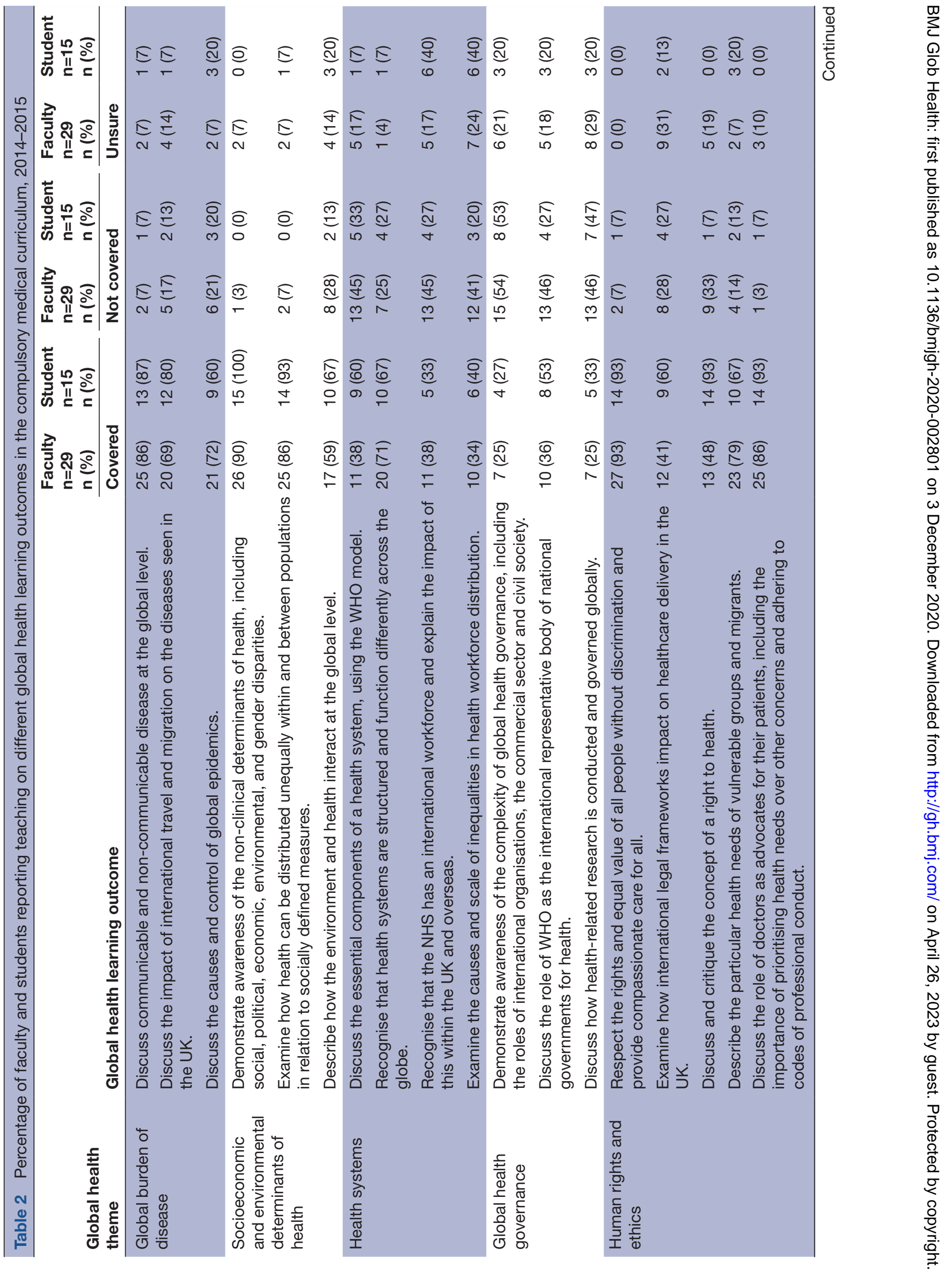




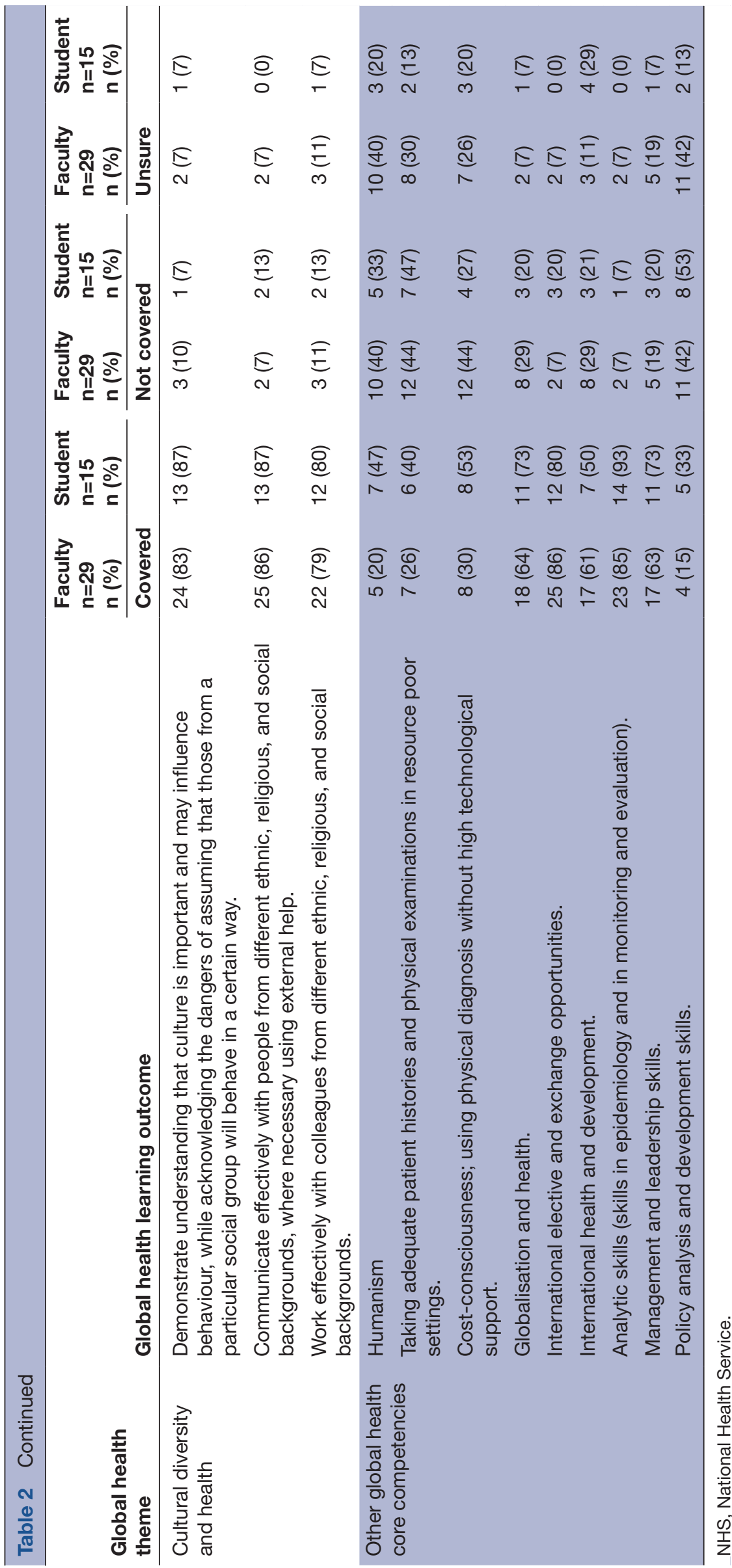


Table 3 Number and percentage of faculty and students reporting forms of optional global health education (GHE) in the medical curriculum, 2014-2015

\begin{tabular}{llc}
\hline Form of optional GHE & $\begin{array}{l}\text { Faculty } \mathbf{n = 2 6} \\
\mathbf{n}(\%)\end{array}$ & $\begin{array}{l}\text { Student } \mathbf{n = 1 3} \\
\mathbf{n}(\%)\end{array}$ \\
\hline SSC/SSM & $23(88)$ & $9(69)$ \\
$\begin{array}{l}\text { Intercalated degree } \\
\text { programme }\end{array}$ & $14(54)$ & $11(85)$ \\
Other & $6(23)$ & $3(23)$ \\
\hline
\end{tabular}

SSC, Student Selected Component; SSM, Special Study Module.

noted there was a need for improving their pre-elective training in its current form (table 4).

\section{DISCUSSION}

\section{Principal findings}

According to faculty and students, global health was included in the core curriculum across $83 \%$ and $67 \%$ of UK medical schools, and almost all institutions offered optional programmes. Despite this, there was large variability in GHE in compulsory curricula, as well as gaps in learning outcomes covered, particularly within the themes of 'Health systems' and 'Global health governance'. Most institutions offered optional teaching and pre-elective training, however, content and delivery were varied.

\section{Comparison with prior studies}

The survey results demonstrated a significant increase in the number of institutions reporting including GHE in the core curriculum-from $24 \%$ in 2006 (4/17 in the survey reported by Dotchin $e t a l^{20}$ ) to $83 \%$ (faculty survey) or $67 \%$ (student survey) in 2015. Core components, however, varied and were more developed in some

Table 4 Themes identified from faculty and student responses to the question 'please give details of any further information you have about pre-elective training for medical students (eg, what are the contents?)'

\begin{tabular}{llr}
\hline Theme & No & \\
\hline Health and safety and risk & Faculty $(n=17)$ & 11 \\
assessment & Students $(n=9)$ & 4 \\
$\leq 1$ day of lectures/workshops & Faculty $(n=17)$ & 7 \\
& Students $(n=9)$ & 5 \\
\hline Planning and logistics & Faculty $(n=17)$ & 6 \\
& Students $(n=9)$ & 3 \\
\hline Disease in a global context & Faculty $(n=17)$ & 1 \\
& Students $(n=9)$ & 4 \\
Elective ethics & Faculty $(n=17)$ & 5 \\
& Students $(n=9)$ & 0 \\
\hline Cultural awareness & Faculty $(n=17)$ & 3 \\
& Students $(n=9)$ & 0 \\
\hline
\end{tabular}

areas than others. These results support past surveys suggesting variations in GHE across institutions: the 2006 survey of 27 medical schools ${ }^{20}$ and a 2014/2015 unpublished review of GHE at medical schools in Scotland (Nugent C, Thomas E, 2015). The former showed that of 17 responding institutions, five had established optional components that included global health and, although all medical schools reported the inclusion of a potential overseas elective period, only 11 had optional or compulsory global health sessions tied to electives. ${ }^{20}$ The latter survey again identified the heterogeneous nature of GHE, as well as the varying elective options and practices among Scottish medical schools (Nugent C, Thomas E, 2015)

Numerous articles reported the presence of elective programmes, often spent abroad, as an established part of most, if not all, UK medical curricula and an opportunity for experiential global health learning. ${ }^{2} 92134-37$ For instance, a 2008 study found that $65 \%(13 / 20)$ of responding medical schools provided specific pre-elective training. ${ }^{35}$ Similarly, this current study identified preelective training at $69 \%$ (faculty survey) or $53 \%$ (student survey) of responding institutions (table 1). Despite this, medical school electives have been frequently criticised for their lack of structure or specific educational objectives and poorly researched contribution to GHE. ${ }^{21} 34-3638{ }^{39}$ Moreover, several elective training strategies have been reported to maximise learning benefits and limit unethical practices, including a global health course $^{40}$ and case-based discussions, ${ }^{41}$ as well as postelective debriefing sessions. ${ }^{214}$ Certainly, the study results highlight the variable nature of pre-elective learning opportunities and the breadth of outcomes covered across different medical school curricula. For example, while several medical schools offered a form of in-person training, some reported providing online or written materials. Also, faculty and student responses combined mostly indicated training addressed the more operational themes of 'Health and safety and risk assessment' and 'Planning and logistics', with fewer responses referring to the broader global health competencies 'Disease in a global context', 'Elective ethics' and 'Cultural awareness', among others (table 4). This is demonstrative of the lack of collective agreement on best practice for elective programmes which prompted the formation of the 2018 consensus document offering recommendations to all UK medical schools. This guidance was based on the collective experience of the UK Medical Schools Council (MSC) Electives Committee, as well as recommendations from SfGH and provides a standard for a more structured approach to electives. ${ }^{43}$

SfGH was established and active at $85 \%$ of responding medical schools, indicating significant interest regarding global health among medical students. Additionally, surveys of medical students at Newcastle University ${ }^{44}$ and King's College London ${ }^{9}$ found dissatisfaction with global health teaching and that most would welcome increased GHE in both the core and optional curriculum. 
Literature shows the development of new global health programmes commonly coincides with pressure from SfGH members and their enthusiastic attempts to introduce global health topics to all medical students. ${ }^{5}{ }^{18-20} 29$ In 2000, advocates from SfGH prompted the creation of a centre at University College London dedicated to bringing global health teaching to the medical curriculum. This led to the introduction of optional special modules on global health topics, structured elective training, and in 2001, the first intercalated BSc in International Health. ${ }^{5}{ }^{18}$ Dotchin $e t a l^{20}$ described the growth of GHE at Newcastle University medical school following a student successfully requesting to study a global health SSC. The SSC became progressively more popular, and students lobbied for the inclusion of more global health in the compulsory curriculum, resulting in increased formal global health teaching for all medical students. ${ }^{20}$ A review of GHE in US medical schools found that despite the substantial presence of student global health interest groups, medical schools remained slow to introduce standardised curricula. ${ }^{27}$ It is, therefore, encouraging that this study highlights a decade of almost $60 \%$ increase in faculty reporting the inclusion of global health in UK core medical curricula.

\section{Implications for policy-makers}

There is still no consensus on the definition of global health, ${ }^{45-48}$ complicating reviews of GHE to date.
Moreover, while the term global health is derived from 'international health' and 'public health' concepts with historical emphasis on hygiene and tropical medicine, it has evolved to encompass a broader range of disciplines away from just biomedicine, including sociology, economics, anthropology and political science. ${ }^{149}$ According to Koplan et al, ${ }^{1}$ without a common definition, it is not possible to agree on what global health is trying to achieve, and how best to achieve this, however, Rowson et al warn the term should not be too prescriptive as meaning will shift depending on the position of the actors studying it. ${ }^{49}$ Figure 1 shows that on average, 39\% and $49 \%$ of faculty reported no teaching on outcomes within the recommended global health themes 'Health systems' and 'Global health governance', respectively. Furthermore, $16 \%$ and $23 \%$ of faculty were unsure if the medical course covered learning outcomes within the themes 'Health systems' and 'Global health governance', while $40 \%$ and $42 \%$ of faculty were unsure about the core competencies: 'Humanism' and skills in 'Policy analysis and development' (table 2). Hence, the ranging nature of GHE at UK medical schools and lack of insight regarding specific global health themes and objectives, suggest a variable understanding of what constitutes 'global health' and comprehensive GHE among medical educators. Indeed, the much higher proportion of both faculty and students confidently reporting teaching on

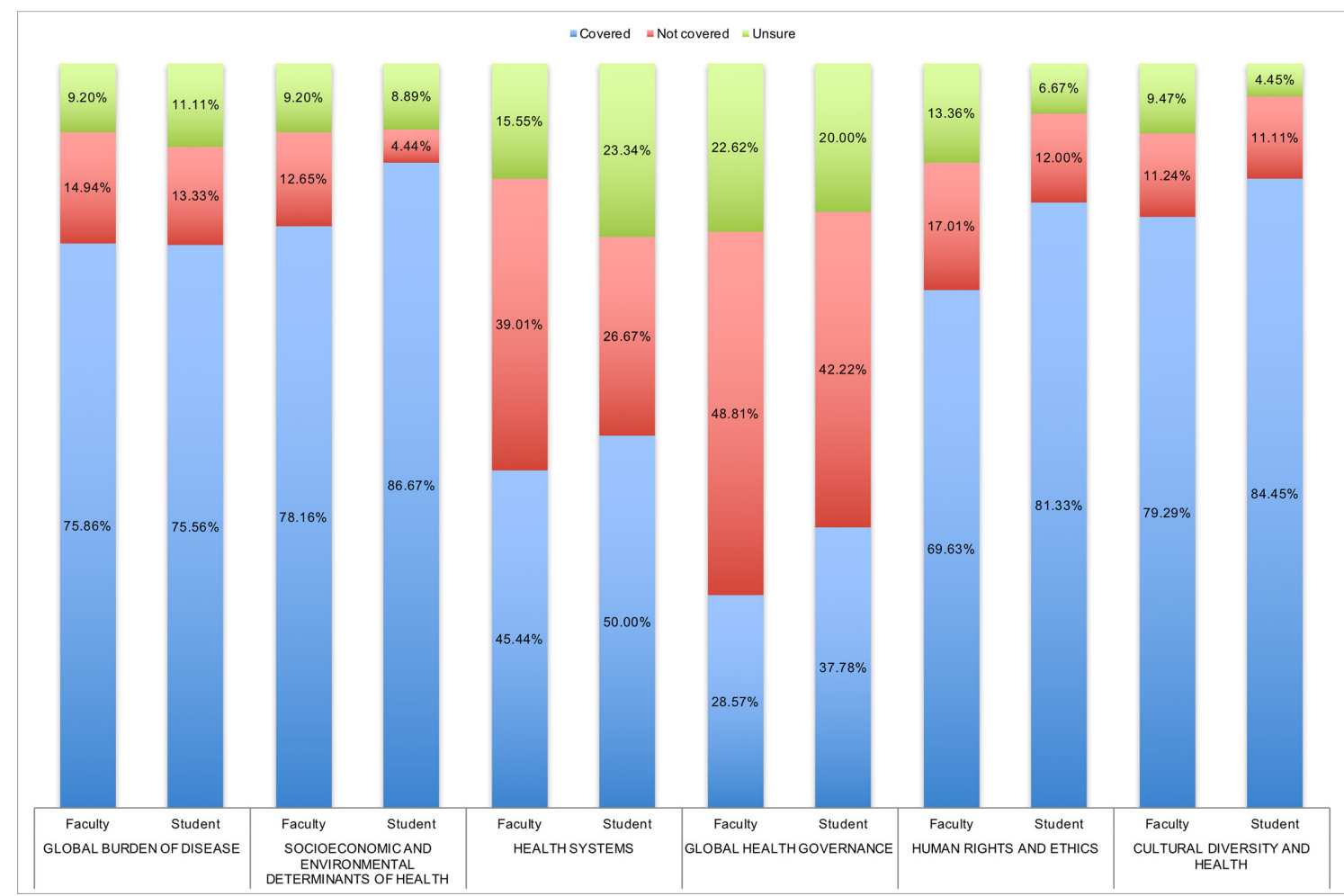

Figure 1 Demonstrates the percentage of learning outcomes covered combined within the six recommended global health themes. ${ }^{32}$ On average, faculty and student reporting showed $76 \%$ or $82 \%$ of schools covered the recommended global health themes 'global burden of disease', 'socioeconomic and environmental determinants of health', human rights and ethics' and 'cultural diversity and health', while only $48 \%$ or $33 \%$ provided teaching on 'health systems' and 'global health governance', respectively. 
the 'Global burden of disease' and 'Socioeconomic and environmental determinants of health' may be indicative of perceptions of global health more in line with previous biomedical conceptions of 'international health' and 'public health'. Furthermore, Harmer et a $\hat{l}^{3}$ attribute confusion surrounding what is new about GHE to a phenomenon of universities 'rebranding' long-standing programmes to meet rising demand for GHE, but without critical distinction between 'international' and 'global' health. This has led to the persistent favouring of traditional 'international health' and 'public health' subjects, such as epidemiology and infectious disease control. ${ }^{3}$

An evolving body of research asserts that effective clinical leadership improves the performance of healthcare organisations. Evidence from McKinsey and the London School of Economics shows that UK hospitals with a greater proportion of clinically trained managers scored higher on drivers of performance than hospitals with low levels of clinical leadership. ${ }^{50}$ It is, therefore, promising that $63 \%$ of faculty and $73 \%$ of students recounted training in management and leadership skills (table 2). However, the high proportion of faculty and students reporting 'no' or 'unsure' regarding learning outcomes within 'Health systems' and 'Global health governance', as well as skills in 'Policy analysis and development' presents a concern as to whether such training in management and leadership is sufficient. Arguably clinical leaders or as Rowson $e t a l^{2}$ coined 'the policy doctor'-doctors working in decision-making posts in institutions of global health research, aid and governance and national Ministries of Health-have a need for broader training in these aspects of global health. Indeed, concerns have been raised regarding the dominance of doctors in policy-making, without adequate training in GHE, leading to inappropriate medicalisation of policy and inadequate solutions to improve global health. ${ }^{451}$

Existing literature suggests that the elective was the most commonly used approach for providing GHE, ${ }^{46}$ however, global health competencies should be integrated into the overall medical curriculum, rather than isolated in the elective period alone. ${ }^{3852}$ Like Harmer $e t$ $a l,{ }^{3}$ this review concludes a need for medical schools to critically evaluate and distinguish between 'global health', 'international health' and 'public health' when planning and implementing core GHE. This is necessary alongside formal GMC guidance and regulation of global health teaching in compulsory curricula to ensure that students are well equipped to tackle the global health challenges of our society. Furthermore, institutions must engage in deeper reflection about the design and management of elective programmes, considering principles outlined in the MSC Electives Committee consensus statement, ${ }^{43}$ to ensure this opportunity for effective experiential GHE is not missed.

\section{Strengths and weaknesses of the study}

It is probable that not all GHE-related activities for UK medical students were identified. The review did not focus on systematically reviewing the content of optional teaching and pre-elective training available to medical students, as this was outside the scope of the research. We believed that a more detailed survey would have a significantly lower response rate, given the limited timescale for staff and students to complete the survey. Furthermore, we thought that it would not be possible to collect a representative sample of final year students (who have experienced most teaching) from each medical school, in the time provided. Therefore, the chosen approach of contacting the final year medical student representative had the important advantage of reducing the likelihood of receiving a biased sample of responses, in which students with a greater interest in global health may have been more willing to complete the survey. Unfortunately, several institutions declined to circulate the survey to the final year medical student representative, as the data collection overlapped with their exams or elective period; thus, there was a lower response rate among students.

There was an inherent risk of reporting bias as those who completed the survey were likely to have an interest in global health, and therefore, may have under-reported or over-reported GHE, in order to expose a greater need for GHE or to ensure their institution did not reflect poorly in the analysis. To minimise this, respondents were assured that the survey data would be presented anonymously and respective universities would not be named. Although there may be varying accuracy in students' recollection of GHE through their 5 years of study, as well as differences in interpretation of the meaning of learning outcomes/competencies, table 2 comparing faculty and student responses shows that student reporting of learning outcomes/competencies covered was largely consistent with the faculty response. The smaller sample size of students, however, meant the results might not be sufficiently powered to detect differences between the groups. The survey design did not account for those institutions whose medical course runs shorter than 5 years of study. Thus, figure 2 includes responses from three institutions with less than 5 years of medical study and will likely underrepresent the number of schools reporting learning outcomes, grouped into global health themes, in year 5 .

It is difficult to assess the presence of all student global health organisations, and there are few records available. Hence, this study focused on SfGH, as perhaps the most established global health organisation advocating for curriculum change. It is, however, important to note that other student-led global health initiatives have developed across the UK such as the global health think tank, Polygeia. $^{53}$

\section{Future research directions}

While the demonstrable increase in global health teaching is promising, this does not certify that current teaching practices are wholly appropriate. Despite advances in the definition of global health, there remains a focus on global health as "public health somewhere 


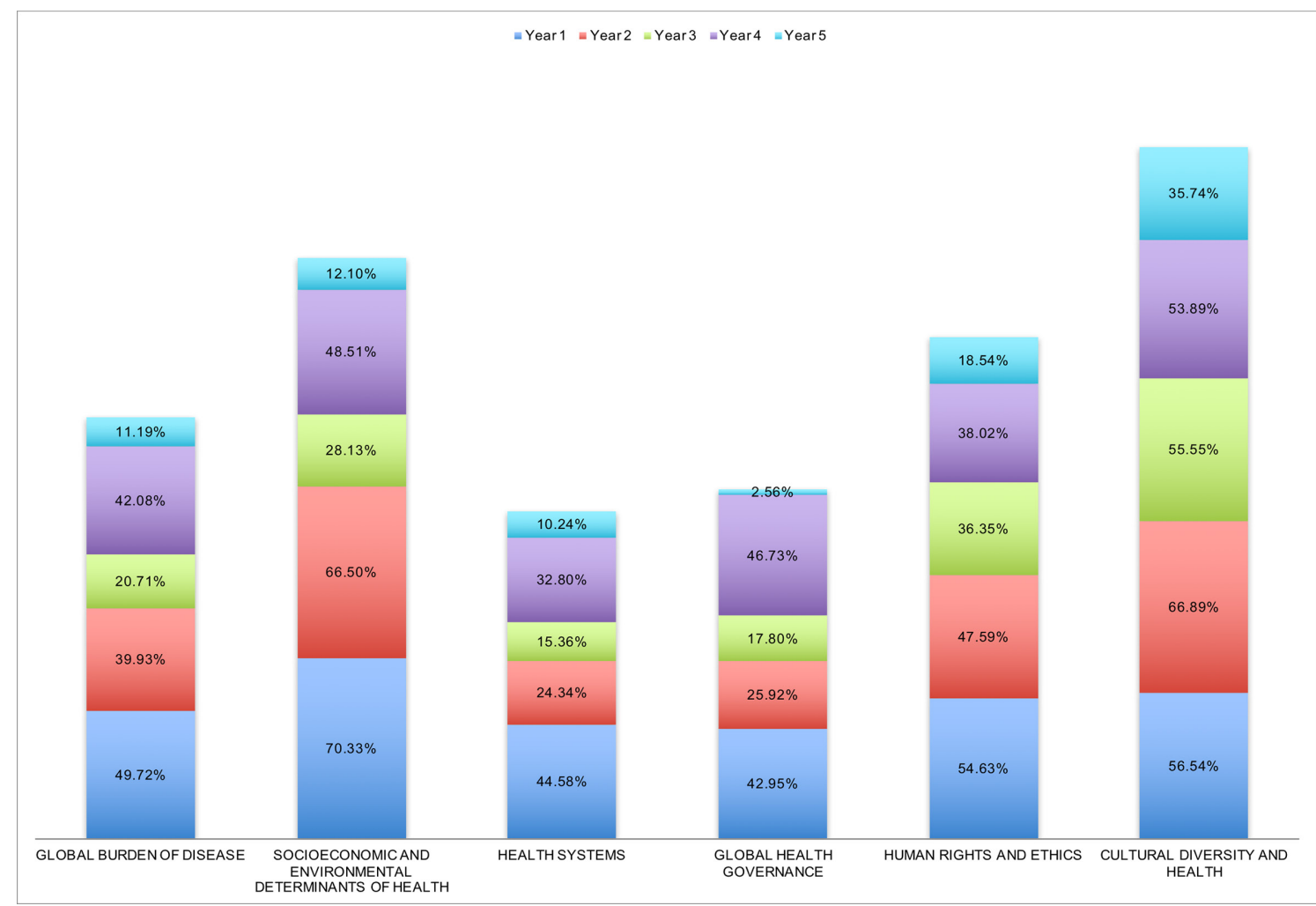

Figure 2 Summarises faculty reporting of the most common location of learning outcomes, grouped into global health themes, throughout years 1-5 of the medical curriculum. Learning outcomes within the themes 'human rights and ethics' and 'cultural diversity and health' were most evenly spread throughout all 5 years of study. All other themes, however, had seemingly less coverage, particularly in years 3 and 5 of the curriculum.

else $^{54}$ including international medical electives, often carried out in low-income and middle-income countries, that may perpetuate imbalanced power dynamics between host and sending institutions. Indeed, the growing movement to 'decolonise global health', led by students and other professionals, demands global health practitioners and institutions must meaningfully address colonial systems that drive health inequities. ${ }^{55}$ This includes engaging with the impact of colonialist legacies on global health curricula and programmes in medical education. ${ }^{56}{ }^{57}$ As Eichbaum et al write, 'the continuing growth in GHE necessitates fresh evaluation of these power dynamics'.

Further exploration of the impact of student global health organisations on the growth of GHE is required. Future studies should involve qualitative analysis of information reported on student advocacy for GHE, as well as case studies of successful campaigns. Additionally, studies should address the barriers faced by medical students trying to improve GHE and identify key components for success to inform future advocates. For example, work by the IFMSA GHE Small Working Group Project Team highlighted that having a "champion' faculty member was a positive predictor for success and when student groups defined comprehensive aims, these aims were more likely to be achieved (Thomas E, Nugent C, Lee W, et al, 2014).

\section{CONCLUSION}

Despite interest in global health among medical students, significant gaps are apparent in current GHE, and there is marked variation in pre-elective training content and delivery. Traditional 'international health' and 'public health' issues such as tropical medicine, epidemiology and the wider social determinants of health are well covered alongside cultural awareness and ethics; however, health systems and global health governance topics are covered much less. This may be indicative of a lack of consensus on the definition of 'global health' and what constitutes appropriate global health training for medical students. There is, therefore, still a need to formalise global health in compulsory curricula. In particular, medical schools need to further recognise the importance of teaching students skills to lead and contribute to global institutions, including the UK NHS. Governing bodies in medical education should establish a comprehensive national strategy to help improve access to fundamental GHE for all medical students.

Twitter Natasha Roya Matthews @n_r_matthews

Contributors HW and NRM designed the study. All authors contributed to the design of the methodology. NRM led the data collection and analysis, wrote the original draft and oversaw the editing of the final manuscript. All authors contributed to the drafting and revision of the article, and read and approved the final manuscript. 
Competing interests NRM is an alumnus of Students for Global Health (formerly Medsin) and the International Federation of Medical Students' Associations (IFMSA). HW is Director of Education for the School of Public Health and founder/director of the BSc in Global Health, the Global Master of Public Health and a short course in Global Health at Imperial College London.

Patient and public involvement Patients and/or the public were involved in the design, or conduct, or reporting, or dissemination plans of this research. Refer to the Methods section for further details.

Patient consent for publication Not required.

Provenance and peer review Not commissioned; externally peer reviewed.

Data availability statement Individual participant data collected during the trial, after deidentification, are available on request to researchers who provide a methodologically sound proposal. Proposals should be directed to the corresponding author at h.ward@imperial.ac.uk.

Open access This is an open access article distributed in accordance with the Creative Commons Attribution Non Commercial (CC BY-NC 4.0) license, which permits others to distribute, remix, adapt, build upon this work non-commercially, and license their derivative works on different terms, provided the original work is properly cited, appropriate credit is given, any changes made indicated, and the use is non-commercial. See: http://creativecommons.org/licenses/by-nc/4.0/.

ORCID iD

Natasha Roya Matthews http://orcid.org/0000-0003-2170-9011

\section{REFERENCES}

1 Koplan JP, Bond TC, Merson MH, et al. Towards a common definition of global health. Lancet 2009;373:1993-5.

2 Rowson M, Smith A, Hughes R, et al. The evolution of global health teaching in undergraduate medical curricula. Global Health 2012;8:35.

3 Harmer A, Lee K, Petty N. Global health education in the United Kingdom: a review of university undergraduate and postgraduate programmes and courses. Public Health 2015;129:797-809.

4 Haq C, Rothenberg D, Gjerde C, et al. New world views: preparing physicians in training for global health work. Fam Med 2000;32:566-72.

5 Bateman C, Baker T, Hoornenborg E, et al. Bringing global issues to medical teaching. Lancet 2001;358:1539-42.

6 Jessop V, Johnson O. Tomorrow's doctors: a global perspective. Lancet 2009;373:1523.

7 McAlister CC, Orr K. A student's plea for global health studies in the medical school curriculum. Clin Invest Med 2006;29:185-6.

8 Drain PK, Primack A, Hunt DD, et al. Global health in medical education: a call for more training and opportunities. Acad Med 2007:82:226-30.

9 Tissingh EK. Medical education, global health and travel medicine: a modern student's experience. Travel Med Infect Dis 2009;7:15-18.

10 Frenk J, Chen L, Bhutta ZA, et al. Health professionals for a new century: transforming education to strengthen health systems in an interdependent world. Lancet 2010;376:1923-58.

11 Willott C, Blum N, Burch W, et al. The Global Doctor. London: UCL Institute for Global Health and Development Education Research Centre, Institute of Education, 2012.

12 Donaldson L, Banatvala N. Health is global: proposals for a UK Government-wide strategy. Lancet 2007;369:857-61.

13 HM Government. Health is global: UK global health strategy 20082013, 2008. Available: https://webarchive.nationalarchives.gov.uk/ 20130105191920/http://www.dh.gov.uk/en/Publicationsandstati stics/Publications/PublicationsPolicyAndGuidance/DH_088702 [Accessed 5 May 2019].

14 HM Government. Health is global: an outcomes framework for global health 2011-2015, 2011. Available: https://assets.publishing.service. gov.uk/government/uploads/system/uploads/attachment_data/file/ 215656/dh_125671.pdf [Accessed 5 May 2019].

15 Educating doctors for World health. Lancet 2001;358:1471.

16 Stigler FL, Duvivier RJ, Weggemans M, et al. Health professionals for the 21st century: a students' view. Lancet 2010;376:1877-8.

17 Bjegovic-Mikanovic V, Jovic-Vranes A, Czabanowska K, et al. Education for public health in Europe and its global outreach. Glob Health Action 2014;7:23570.
18 Yudkin JS, Bayley O, Elnour S, et al. Introducing medical students to global health issues: a Bachelor of science degree in international health. Lancet 2003;362:822-4.

19 Watts G. Raising horizons. BMJ 2004;329:1366.1.

20 Dotchin C, van den Ende C, Walker R. Delivering global health teaching: the development of a global health option. Clin Teach 2010;7:271-5.

21 Evans R, Dotchin C, Walker R. Maximising the value from the elective experience: post-elective workshops. Clin Teach 2013;10:362-7.

22 Duvivier R, Brouwer E, Weggemans M. Medical education in global health: student initiatives in the Netherlands. Med Educ 2010;44:528-9.

23 Sooknanan A, Pai N. Medical students reach out for global health. Can Fam Physician 2007;53:1975-6.

24 Izadnegahdar R, Correia S, Ohata B, et al. Global health in Canadian medical education: current practices and opportunities. Acad Med 2008;83:192-8.

25 Fox GJ, Thompson JE, Bourke VC, et al. Medical students, medical schools and international health. Med J Aust 2007;187:536-9.

26 Bozorgmehr K, Schubert K, Menzel-Severing J, et al. Global Health Education: a cross-sectional study among German medical students to identify needs, deficits and potential benefits (Part 1 of 2: Mobility patterns \& educational needs and demands). BMC Med Educ 2010;10:66

27 Khan OA, Guerrant R, Sanders J, et al. Global health education in U.S. medical schools. BMC Med Educ 2013;13:3.

28 Students for global health. history. Available: https://studentsforg lobalhealth.org/history/ [Accessed 5 May 2019].

29 Garman K, Hughes R, Medicine HR. Medicine, Medsin, and global health. Lancet 2006;368:103-4

30 Medsin. Gh in curriculum. Available: http://medsin.org/educate/ global-health-in-medical-curriculum [Accessed 1 April 2015].

31 General Medical Council. Tomorrow's Doctors: outcomes and standards for undergraduate medical education. London: General Medical Council, 2009.

32 Johnson O, Bailey SL, Willott C, et al. Global health learning outcomes for medical students in the UK. Lancet 2012;379:2033-5.

33 Eaton DM, Redmond A, Bax N. Training healthcare professionals for the future: internationalism and effective inclusion of global health training. Med Teach 2011;33:562-9.

34 Miranda JJ, Yudkin JS, Willott C. International health electives: four years of experience. Travel Med Infect Dis 2005;3:133-41.

35 Banerjee A, Banatvala N, Handa A. Medical student electives: potential for global health? Lancet 2011;377:555

36 Coltart CEM, Black ME, Easterbrook PJ. Global health in the UK government and university sector. Infect Dis Clin North Am 2011;25:555-74.

37 Hastings A, Dowell J, Eliasz MK. Medical student electives and learning outcomes for global health: a commentary on behalf of the UK medical schools elective Council. Med Teach 2014;36:355-7.

38 Edwards R, Piachaud J, Rowson M, et al. Understanding global health issues: are international medical electives the answer? Med Educ 2004;38:688-90.

39 Dowell J, Merrylees N. Electives: isn't it time for a change? Med Educ 2009;43:121-6.

40 Nelson BD, Saltzman A, Lee PT. Bridging the global health training gap: design and evaluation of a new clinical global health course at Harvard medical school. Med Teach 2012;34:45-51.

41 White M, Evert J. Developing ethical awareness in global health: four cases for medical educators. Dev World Bioeth 2014;14:111-6.

42 Miller C, Satterfield C, Patel P, et al. Reflection and Debriefing: tools for fostering student emotional learning during and after international health electives. Ann Glob Health 2015;81:162-3.

43 Wiskin C, Barrett M, Fruhstorfer B, et al. Recommendations for undergraduate medical electives: a UK consensus statement. Med Educ 2018;52:14-23.

44 Edwards R, Rowson M, Piachaud J. Teaching international health issues to medical students. Med Educ 2001;35:807-8.

45 Beaglehole R, Bonita R. What is global health? Glob Health Action 2010;3:5142.

46 Liu Y, Zhang Y, Liu Z, et al. Gaps in studies of global health education: an empirical literature review. Glob Health Action 2015;8:25709.

47 Abimbola S. The information problem in global health. BMJ Glob Health 2016;1:e900001.

48 Taylor S. 'Global health': meaning what? BMJ Glob Health 2018;3:e000843.

49 Rowson M, Willott C, Hughes R, et al. Conceptualising global health: theoretical issues and their relevance for teaching. Global Health 2012;8:36. 
50 Castro PJ, Dorgan SJ, Richardson B. A healthier health care system for the United Kingdom, 2008. Available: https://washburn.edu/ faculty/rweigand/McKinsey/McKinsey-Healthier-Care-In-UK.pdf [Accessed 28 Jul 2020].

51 People's Health Movement, Medact, Medico International. E1: the World Health Organization. In: Global health Watch 2005-06: an alternative World health report. London: Zed Books, 2005. https:// www.zedbooks.net/shop/book/global-health-watch-2005-06/

52 Peluso MJ, Encandela J, Hafler JP, et al. Guiding principles for the development of global health education curricula in undergraduate medical education. Med Teach 2012;34:653-8.

53 Polygeia. Polygeia: students shaping global health policy. Available: https://www.polygeia.com/ [Accessed 5 May 2019].

54 King NB, Koski A. Defining global health as public health somewhere else. BMJ Glob Health 2020;5:e002172.

55 Büyüm $\mathrm{AM}$, Kenney $\mathrm{C}$, Koris $\mathrm{A}$, et al. Decolonising global health: if not now, when? BMJ Glob Health 2020;5:e003394
56 Herzig van Wees S, Holmer H. Global health beyond geographical boundaries: reflections from global health education. BMJ Glob Health 2020;5:e002583.

57 Eichbaum QG, Adams LV, Evert J, et al. Decolonizing global health education: rethinking institutional partnerships and approaches. Acad Med 2020. doi:10.1097/ACM.0000000000003473. [Epub ahead of print: 28 Apr 2020].

58 Battat R, Seidman G, Chadi N, et al. Global health competencies and approaches in medical education: a literature review. BMC Med Educ 2010;10:94.

59 Global Health Education Consortium. Global health essential core competencies, 2010. Available: http://globalhealtheducation. org/resources/Documents/Primarily For Faculty/Basic Core_ Competencies_Final 2010.pdf [Accessed 1 Mat 2015].

60 Pfeiffer J, Beschta J, Hohl S, et al. Competency-Based curricula to transform global health: redesign with the end in mind. Acad Med 2013;88:131-6. 